\title{
QUEEN'S
UNIVERSITY
BELFAST
}

\section{Modelling and experimental validation on drilling delamination of aramid fiber reinforced plastic composites}

Liu, S., Tao, Y., Liu, C., Jin, Y., Sun, D., \& Shen, Y. (2020). Modelling and experimental validation on drilling delamination of aramid fiber reinforced plastic composites. Composite Structures.

https://doi.org/10.1016/j.compstruct.2020.111907

\section{Published in:}

Composite Structures

\section{Document Version:}

Peer reviewed version

\section{Queen's University Belfast - Research Portal:}

Link to publication record in Queen's University Belfast Research Portal

\section{Publisher rights}

Copyright 2020 Elsevier.

This manuscript is distributed under a Creative Commons Attribution-NonCommercial-NoDerivs License

(https://creativecommons.org/licenses/by-nc-nd/4.0/), which permits distribution and reproduction for non-commercial purposes, provided the author and source are cited.

\section{General rights}

Copyright for the publications made accessible via the Queen's University Belfast Research Portal is retained by the author(s) and / or other copyright owners and it is a condition of accessing these publications that users recognise and abide by the legal requirements associated with these rights.

Take down policy

The Research Portal is Queen's institutional repository that provides access to Queen's research output. Every effort has been made to ensure that content in the Research Portal does not infringe any person's rights, or applicable UK laws. If you discover content in the Research Portal that you believe breaches copyright or violates any law, please contact openaccess@qub.ac.uk. 


\section{Journal Pre-proofs}

Modelling and experimental validation on drilling delamination of aramid fiber reinforced plastic composites

Sinan Liu, Tao Yang, Chang Liu, Yan Jin, Dan Sun, Yifei Shen

PII:

S0263-8223(19)32526-7

DOI: https://doi.org/10.1016/j.compstruct.2020.111907

Reference:

COST 111907

To appear in:

\section{Composite Structures}

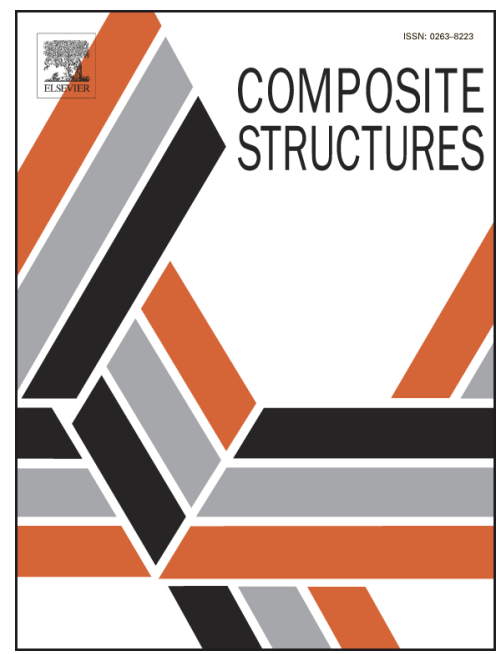

Received Date: $\quad 3$ July 2019

Revised Date: $\quad 5$ December 2019

Accepted Date: $\quad 8$ January 2020

Please cite this article as: Liu, S., Yang, T., Liu, C., Jin, Y., Sun, D., Shen, Y., Modelling and experimental validation on drilling delamination of aramid fiber reinforced plastic composites, Composite Structures (2020), doi: https:// doi.org/10.1016/j.compstruct.2020.111907

This is a PDF file of an article that has undergone enhancements after acceptance, such as the addition of a cover page and metadata, and formatting for readability, but it is not yet the definitive version of record. This version will undergo additional copyediting, typesetting and review before it is published in its final form, but we are providing this version to give early visibility of the article. Please note that, during the production process, errors may be discovered which could affect the content, and all legal disclaimers that apply to the journal pertain.

(C) 2020 Published by Elsevier Ltd. 


\title{
Modelling and experimental validation on drilling delamination of aramid fiber reinforced plastic composites
}

Sinan Liu ${ }^{\mathrm{a}, \mathrm{b}}$, Tao Yang ${ }^{\mathrm{a}}$, Chang Liu ${ }^{\mathrm{a}, *}$, Yan Jin ${ }^{\mathrm{b}}$, Dan Sun ${ }^{\mathrm{b}}$, Yifei Shen ${ }^{\mathrm{a}}$

a School of Mechanical Engineering, Tianjin Polytechnic University, Tianjin 300387, China

b School of Mechanical and Aerospace Engineering, Queen's University Belfast, BT9 5AH, UK

*Corresponding author

E-mail address: liuchang@tjpu.edu.cn (C. Liu)

\begin{abstract}
Aramid fiber reinforced plastic (AFRP) composites have been widely used in aerospace, military, and automotive industries. The common drilling process deployed for AFRP manufacturing can induce delamination that drastically deteriorate the mechanical performance and fatigue lives of the drilled AFRP components, therefore, establishing an accurate delamination model is desirable for delamination suppression and hole quality optimization. However, existing delamination models sum up all loads of the chisel edge and cutting lips act on the uncut plies under the chisel edge algebraically, which does not represent the true contact conditions. In this study, a new delamination regime is proposed where delamination caused by thrust forces exerted by both the chisel edge and cutting lips have been considered. On this basis, a novel analytical model in the context of AFRP drilling is proposed for the critical thrust force (CTF) prediction. Double cantilever beam (DCB) and delamination tests have been performed to validate the new model and results show that our proposed model agrees
\end{abstract}




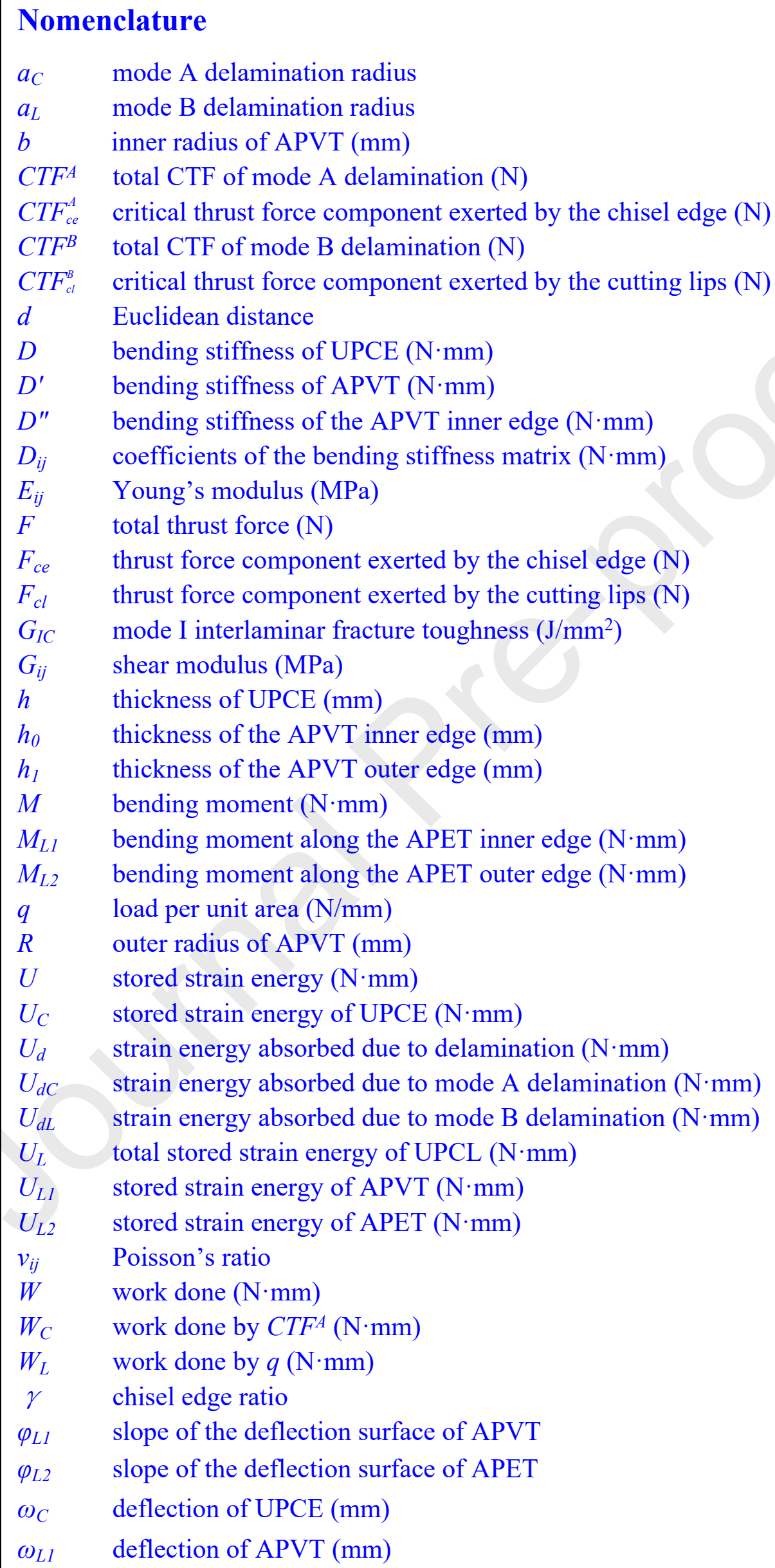


highly with the experimental results where the thrust force exerted by the chisel edge accounts for $24 \%$ of the total load during drilling of AFRP.

\section{Keywords}

AFRP composites, Drilling, Delamination, Critical thrust force, Analytical model

\section{Introduction}

With their excellent specific strength and toughness, aramid fiber reinforced plastic (AFRP) composites have been widely used in aerospace, military, and automotive industries [1]. To date, drilling is still considered as the most pivotal process in manufacturing/assembly of AFRP components due to its high efficiency [2]. However, the multiphase / anisotropic structure of AFRP often leads to undesirable manufacturing defects such as fuzzing, tearing, delamination and thermal degradation [3]. Delamination is one of the most critical defects which can drastically deteriorate the mechanical performance of the drilled components, particularly their fatigue lives, hence limiting their further applications.

With the aim of minimizing drilling damage in AFRP, some researchers have studied AFRP drilling parameters optimization and hole quality control. For instance, Won and Dharan [4] compared the hole quality of AFRP and carbon fiber reinforced plastic (CFRP) where the holes were produced under their respective optimal cutting parameters using the same twist drills. They found that while the machined surface of CFRP laminates was relatively smooth, the AFRP workpieces exhibited fuzzy machined surfaces with a large degree of fiber pull-out and crushed aramid fiber bundles. Bhattacharyya and Horrigan [5] investigated the influence of temperature on 
the drilling thrust force and found that greater thrust force is required under cryogenic condition as compared to room temperatures. Shuaib et al. [6] analysed the influences of laminates preparation parameters and drilling conditions on the specific cutting energy, thrust force, and torque during drilling of plain weave AFRP when coated twist drills were used. They concluded that the thrust force and torque increase with increasing cutting speed, feed rate, and laminated thickness. In addition, researchers have investigated the influence of drill bit geometry and drilling parameters (e.g., feed rate $f$, spindle speed $S$ ) on the optimization of thrust force and hole quality. Table 1 provides a further summary on recent research in drilling of AFRP.

While the research into AFRP drilling delamination (especially the development of theoretical delamination models) is still in its infancy, delamination mechanisms of other fiber reinforced plastic (FRP) systems are reasonably well established in the field. Hocheng et al. [14] investigated two different delamination mechanisms in the drilling process of CFRP. It is found that when the tool drills into a laminate, delamination at the entrance plane is induced by the peeling action of the cutting tool. Under the continuous cutting motion at the hole exit, delamination occurs when the thrust force exceeds the interlaminar bonding strength of the laminate. On this basis, Capello [15] analyzed the difference in delamination mechanisms between drilling glass fiber reinforced plastic (GFRP) with and without a supporting plate. The study suggests that the cutting action of the drill point turns into punching action when the feed speed reaches a threshold value. Therefore, delamination is a consequence of overload on the peripheral parts of the cutting edge. The location of delamination defects has been also 
investigated [16-19]. Wang et al., through C-scanning and SEM analysis, [18] suggests that the presence of inter-laminates delamination in drilling of CFRP depends on the drilling parameters and the cutting capability of the tools. In order to analyze the origin of crack initiation, Girot et al. [19] compared the machining morphologies and reported that delamination crack initiates at the drill corner as the drill bit exits the work piece.

To restrain delamination damage, it is important to predict the thrust force at the onset of delamination and control the thrust force during the drilling process $[20,21]$. For this purpose, some workers have developed analytical models for delamination in drilling of CFRP. The first critical thrust force (CTF) model was presented by Ho-cheng and Dharan [14]. By assuming isotropy of the material and application of point load, this model gives a conservative prediction of the CTF. On this basis, Zhang et al. [22] took into account the material anisotropy and the coupling between tension and bending during drilling of CFRP, and established the delamination model for unidirectional laminates with an elliptical crack. Lachaud et al. [23] made the hypotheses that the thrust force exerted by a twist drill can be described by the uniformly distributed load and the point load at the center of the laminate, and established analytical models for both loads. In addition, CTF prediction have also been carried out for new modes of loading (such as triangular loading, combined loading) $[19,24]$, as well as the mixed mode energy release rate $G_{C}[19,25]$, and the thermo-mechanical formulation [26]. Table 2 summarizes the exiting CTF models at onset of delamination in drilling of CFRP. 
Existing literature on delamination mechanism analysis and modelling are based on twist drill. Despite its simple geometry, the analytical research on twist drill delamination mechanism can help to inform the design of special drill geometries for better drilling quality. However, most existing models considered the thrust force exerted by the cutting lips as uniformly distributed load along the X-Y plane under the chisel edge, and neglected the effect of the uncut material in contact with the cutting lips during delamination. In addition, few studies have considered the role of thrust force on the actual tool-material interaction mechanisms in the context of AFRP drilling and their associated delamination model. In view of the limitations in the existing research, two modes of delamination (caused by thrust forces exerted by the chisel edge and cutting lips, respectively) have been investigated in this work, and a novel analytical model for the CTF prediction based on both the chisel edge delamination and the drill corner delamination is proposed. The proposed model has also been verified by the experimental results from double cantilever beam (DCB) and delamination tests in AFRP drilling.

\section{Proposal of new analytical model}

\subsection{Traditional delamination regime}

Fig. 1 illustrates the traditional delamination regime that can be generalized for several existing FRP drilling studies [14, 19-28]. Because the thickness of uncut plies decreases during cutting, the underneath uncut plies may experience deflection under the thrust force. When the thrust force exceeds the interlaminar bonding strength, delamination damage with radius $a$ will occur. In the existing CTF prediction 
models, the interaction between the drill and the uncut materials are mainly modeled by a point load $F_{1}$ at the center of the uncut material $[14,21,22]$, uniformly distributed load $F_{2}$ along the drill radius $R[20,23]$, and/or the combination of the two [19, 24, 29]. However, the traditional delamination regime sums up all loads (exerted by the chisel edge and the cutting lips) act on the uncut plies under the chisel edge (UPCE) algebraically, which does not represent the true contact conditions.

2.2 New proposed delamination regime

\subsubsection{The actual drill/material contact}

Fig. 2 shows the actual drill/laminate contact in drilling of AFRP. Based on the law of superposition of the linear elastic regime, the total thrust force $F$ can be described by Eq. (1):

$$
F=F_{c e}+F_{c l}
$$

where $F_{c e}$ and $F_{c l}$ are the force components of the thrust force exerted by the chisel edge and the cutting lips, respectively. Two different interaction regions and mechanisms of thrust force can be observed. In region 1, the UPCE is subject to $F_{c e}$. In region 2 , the uncut material under the cutting lips (UPCL) is subject to $F_{c l}$. The different geometrical characteristics of the two regions can result in significantly different machining mechanisms and modes of delamination, which have not been discussed by previous studies.

\subsubsection{Mode A delamination}

In this section, a new delamination regime is proposed to analyze the two modes of delamination in their respective interaction region. Based on the classic plate bending theory [30], UPCE and UPCL can be considered as circular plates constrained within 
the laminate. Considering the tool geometry of the twist drill, the thrust force exerted by the chisel edge is assumed as a point load applied at the center of the UPCE, whereas the thrust force exerted by the cutting lips can be described as a uniformly distributed load on the UPCL. When the thrust force reaches a critical value, interfacial debonding occurs between the plies due to the low interfacial bonding strength. As a result, the delamination cracks will be initiated under two modes of delamination respectively, and they will propagate in their respective weakest planes between the plies. The planes of the crack propagation under two modes of delamination are parallel to each other. Therefore, it is assumed that the initiation and propagation of the two modes of delamination are independent.

Fig. 3 shows the proposed mechanism for mode A delamination caused by $F_{c e}$. The UPCE can be modeled as a circular plate. In order to define the contribution of the thrust force component, the chisel edge ratio $\gamma$ is defined as the ratio of $F_{c e}$ and $F$ :

$$
\gamma=\frac{F_{c e}}{F},(0<\gamma<1)
$$

The bending stiffness of the UPCE decreases as the cutting progresses, which makes the uncut material more prone to delamination. When $F_{c e}$ exceeds the critical force component of the thrust force exerted by the chisel edge $\left(C T F_{c e}^{A}\right)$, mode A delamination will occur and propagate with a radius $a_{C}$. Hence the total CTF at the onset of mode A delamination $\left(C T F^{A}\right)$ can be described as:

$$
C T F^{A}=\frac{C T F_{c e}^{A}}{\gamma}
$$

\subsubsection{Mode B delamination}

On the other hand, the proposed mechanism for mode B delamination (caused by 
$F_{c l}$ ) can be described by Fig. 4. The UPCL can be modeled as an annular plate with varying thickness. The material is mainly removed by the drill cutting lips and the support from the UPCE gradually decreases with their reducing thickness (hence reduced bending stiffness). Mode B delamination under action of $F_{c l}$, depends on the interlaminar bonding strength in regions adjacent to the drill corner. When $F_{c l}$ exceeds the critical force component of the thrust force exerted by the cutting lips $\left(C T F_{c l}^{B}\right)$, mode B delamination will initiate and propagate with radius $a_{L}$. The total $\mathrm{CTF}$ at the onset of mode B delamination, $C T F^{B}$, can be described as follows:

$$
C T F^{B}=\frac{C T F_{c l}^{B}}{1-\gamma}
$$

\subsection{Total CTF of mode A delamination, $C T F^{A}$}

Based on linear elastic fracture mechanics (LEFM) and the virtual work theorem [14], the energy conservation follows:

$$
\delta U_{d}=\delta W-\delta U
$$

where $\delta U_{d}$ is the energy absorbed due to delamination propagation, $\delta W$ is the virtual work done by the thrust force, $\delta U$ is the infinitesimal strain energy.

As illustrated in Fig. 5, when subjected to $C T F_{c e}^{A}$, the deflection of UPCE in the case of mode A delamination is given by [30]:

$$
\omega_{C}=\frac{C T F_{c e}^{A}}{16 \pi D}\left[2 r^{2} \ln \left(\frac{r}{a_{C}}\right)+\left(a_{C}{ }^{2}-r^{2}\right)\right]
$$

where

$$
D=\frac{1}{8}\left(3 D_{11}+2 D_{12}+4 D_{66}+3 D_{22}\right)
$$


Coefficients $D_{i j}$ of the bending stiffness matrix can be described as follows [31]:

$$
D_{11}=\frac{E_{11} h^{3}}{12\left(1-v_{12} v_{21}\right)} \quad D_{22}=\frac{E_{22} h^{3}}{12\left(1-v_{12} v_{21}\right)} \quad D_{12}=\frac{v_{12} E_{22} h^{3}}{12\left(1-v_{12} v_{21}\right)} \quad D_{66}=\frac{G_{12} h^{3}}{12}
$$

where $E_{i j}$ and $G_{i j}$ are the elastic modulus of the AFRP laminate, $v_{i j}$ is the Poisson ratio, $h$ is the thickness of UPCE.

The strain energy under $C T F_{c e}^{A}$ follows [20]:

$U_{C}=\pi D \int_{0}^{a_{C}}\left[\left(\frac{d^{2} \omega_{C}}{d r^{2}}+\frac{1}{r} \frac{d \omega_{C}}{d r}\right)^{2}-2(1-v)\left(\frac{d^{2} \omega_{C}}{d r^{2}} \times \frac{1}{r} \frac{d \omega_{C}}{d r}\right)\right] r \mathrm{~d} r \Rightarrow \delta U_{C}=\frac{\left(C T F_{c e}^{A}\right)^{2} a_{C}}{16 \pi D} \delta a_{C}(9)$

The work done by $C T F_{c e}^{A}$ is:

$$
W_{C}=\frac{\left(C T F_{c e}^{A}\right)^{2} a_{C}^{2}}{16 \pi D} \Rightarrow \delta W_{C}=\frac{\left(C T F_{c e}^{A}\right)^{2} a_{C}}{8 \pi D} \delta a_{C}
$$

The strain energy absorbed during the crack propagation follows:

$$
U_{d C}=G_{I C} \pi a_{C}^{2} \Rightarrow \delta U_{d C}=G_{I C} 2 \pi a_{C} \delta a_{C}
$$

where $G_{I C}$ is the mode I interlaminar fracture toughness. Substituting Eqs. (9)-(11) into Eq. (5), $C T F_{c e}^{A}$ can be obtained:

$$
C T F_{c e}^{A}=4 \pi \sqrt{2 G_{I C} D}
$$

The total CTF for mode A delamination can be described as:

$$
C T F^{A}=\frac{4 \pi \sqrt{2 G_{I C} D}}{\gamma}
$$

2.4 Total CTF of mode B delamination, $C T F^{B}$

As illustrated in Fig. 6, the UPCL can be further decomposed into an annular plate with linearly varying thickness (APVT) and an annular plate with equal thickness (APET).

2.4.1 Annular plate with linearly varying thickness (APVT) 
The analytical model of the APVT is shown in Fig. 7(a). When the plate is subject to $F_{c l}$, load per unit area, $q$, is uniformly distributed along the contact surface between the cutting lips and uncut material. Fig. 7(b) illustrates the geometry of the twist drill used in this study. $h_{0}$ is defined as the height of the chisel edge, and $b$ is the chisel edge radius. Because the uncut material is machined by the cutting lips during drilling, it is assumed that the dimensions of the top surface of APVT complies with the geometry of the twist drill. Therefore, $b$ and $h_{0}$ equal to the inner radius and the thickness of APVT, respectively (see green dashed lines in Fig. 7(a)), and $R$ and $h_{1}$ equal to the outer radius and the thickness of APVT, respectively.

The equilibrium equation for an element of APVT can be described as:

$$
D^{\prime} \frac{d}{d r}\left(\frac{d \varphi}{d r}+\frac{\varphi}{r}\right)+\frac{d D^{\prime}}{d r}\left(\frac{d \varphi}{d r}+v \frac{\varphi}{r}\right)=-\frac{1}{r} \int_{b}^{r} q r d r
$$

where $\varphi$ is the slope of the deflection surface of the APVT. Due to the varying thickness, the bending stiffness $D^{\prime}$ of APVT varies with radical distance $r$ and it can be simplified as [30]:

$$
D^{\prime}=\frac{D^{\prime \prime} r^{3}}{b^{3}}, \quad b \leq r \leq R
$$

The bending stiffness of the APVT inner edge, $D^{\prime \prime}$ can be expressed as:

$$
D^{\prime \prime}=\frac{1}{8}\left(3 D_{11}^{\prime \prime}+2 D_{12}^{\prime \prime}+4 D_{66}^{\prime \prime}+3 D_{22}^{\prime \prime}\right)
$$

where $D_{i j}^{\prime \prime}$ are the coefficients of the bending stiffness matrix at $r=b$.

Substituting Eq. (15) into Eq. (14), the following differential equation can be obtained:

$$
\frac{D^{\prime \prime} r^{3}}{b^{3}} \frac{d}{d r}\left(\frac{d \varphi}{d r}+\frac{\varphi}{r}\right)+\frac{3 D^{\prime \prime} r^{2}}{b^{3}}\left(\frac{d \varphi}{d r}+v \frac{\varphi}{r}\right)=-\frac{1}{r} \int_{b}^{r} q r d r
$$


By using the Euler equation, the slope of the deflection surface of APVT can be obtained as the general solution of the equation:

$$
\varphi_{L 1}=A r^{K_{1}}+B r^{K_{2}}+q K_{3}-\frac{q K_{4}}{r^{2}}
$$

where

$$
\left\{\begin{array}{l}
K_{1}=\sqrt{3.25-3 v}-1.5 \\
K_{2}=-\sqrt{3.25-3 v}-1.5 \\
K_{3}=\frac{b^{3}}{2 D^{\prime}(1-3 v)} \\
K_{4}=\frac{b^{5}}{6 D^{\prime}(1-v)}
\end{array}\right.
$$

By integrating Eq. (18), the deflection of the APVT subject to $q$ can be described as:

$$
\omega_{L 1}=-\frac{A r^{K_{1}+1}}{K_{1}+1}-\frac{B r^{K_{2}+1}}{K_{2}+1}-K_{3} q r-\frac{K_{4} q}{r}+C
$$

where $A, B, C$ are the integration constants. For the APVT, the strain energy under $q$ can be obtained:

$$
U_{L 1}=\pi \frac{D^{\prime \prime}}{b^{3}} \int_{b}^{R}\left[\left(\frac{d^{2} \omega_{L 1}}{d r^{2}}+\frac{1}{r} \frac{d \omega_{L 1}}{d r}\right)^{2}-2(1-v)\left(\frac{d^{2} \omega_{L 1}}{d r^{2}} \times \frac{1}{r} \frac{d \omega_{L 1}}{d r}\right)\right] r^{4} d r
$$

\subsubsection{Annular plate with equal thickness (APET)}

As shown in Fig. 8, the APET is bent due to the uniformly distributed moment $M_{L 1}$ originated from $q$. Furthermore, since APET is constrained, it will be subject to the uniform bending moments $M_{L 2}$ along the outer edge.

In this case, the bending moments acting on the circumferential sections of the UPCL can be expressed as [30]: 


$$
M=D^{\prime}\left(\frac{\partial \varphi}{\partial r}+\frac{\nu}{r} \varphi\right)
$$

Under such a condition, the slope of the deflection surface of APET can be written as:

$$
\varphi_{L 2}=\frac{A^{\prime} r}{2}+\frac{B^{\prime}}{r}, R \leq r \leq a_{L}
$$

where $R$ and $a_{L}$ can be described by the following relationship:

$$
s=R / a_{L}
$$

By integrating Eq. (23), the deflection of the APET can be obtained:

$$
\omega_{L 2}=-\frac{A^{\prime} r^{2}}{4}-B^{\prime} \ln \frac{r}{a_{L}}+C^{\prime}
$$

where $A^{\prime}, B^{\prime}, C^{\prime}$ are integration constants. For the APET, the strain energy can be calculated as follows:

$$
U_{L 2}=\pi \frac{D^{\prime \prime} R^{3}}{b^{3}} \int_{R}^{a_{L}}\left[\left(\frac{d^{2} \omega_{L 2}}{d r^{2}}+\frac{1}{r} \frac{d \omega_{L 2}}{d r}\right)^{2}-2(1-v)\left(\frac{d^{2} \omega_{L 2}}{d r^{2}} \times \frac{1}{r} \frac{d \omega_{L 2}}{d r}\right)\right] r d r
$$

\subsubsection{Determination of integration constants}

Conditions for solving the six integration constants $\left(A, B, C, A^{\prime}, B^{\prime}, C^{\prime}\right)$ at the boundaries $\left(r=b\right.$ and $\left.r=a_{L}\right)$, and the interface $(r=R)$ are shown in Fig. 9.

The slope and the deflection of APET at $r=a_{L}$ is zero. Moreover, considering the constraint at the contact point between the chisel edge and the cutting lips, $r=b$, it can be assumed that the deflection of the APVT $\omega_{L 1}$ equals that of the deflection of the circular plate $\omega_{C}$. Therefore, the conditions at $r=a_{L}$ and $r=b$ can be described as:

$$
\left\{\begin{array}{l}
r=a_{L}: \varphi_{L 2}=0 \quad \omega_{L 2}=0 \\
r=b: \quad \omega_{L 1}-\omega_{C}=0
\end{array}\right.
$$

where 


$$
\begin{gathered}
\left.\varphi_{L 2}\right|_{r=a_{L}}=\frac{A^{\prime} a_{L}}{2}+\frac{B^{\prime}}{a_{L}}=0 \\
\left.\omega_{L 2}\right|_{r=a_{L}}=-\frac{A^{\prime} a_{L}^{2}}{4}+C^{\prime} \\
\omega_{L 1}-\left.\omega_{C}\right|_{r=b}=-\frac{A b^{K_{1}+1}}{K_{1}+1}-\frac{B b^{K_{2}+1}}{K_{2}+1}-K_{3} q b-\frac{K_{4} q}{b}+C \\
-\frac{\gamma}{1-\gamma} \cdot \frac{q\left(R^{2}-b^{2}\right)}{16 D^{\prime \prime}}\left[2 b^{2} \ln \left(\frac{b}{R}\right)+\left(R^{2}-b^{2}\right)\right]
\end{gathered}
$$

Furthermore, APVT and APET have the same moment, slope, and deflection when $r=R$. Therefore, the conditions at $r=R$ can be written as:

$$
r=R: M_{L 1}-M_{L 2}=0 \quad \varphi_{L 1}-\varphi_{L 2}=0 \quad \omega_{L 1}-\omega_{L 2}=0
$$

where

$$
\begin{gathered}
M_{L 1}-\left.M_{L 2}\right|_{r=R}= \\
\quad A K_{1} R^{K_{1}-1}+B K_{2} R^{K_{2}-1}+\frac{2 q K_{4}}{R^{3}}+\frac{v}{R}\left(A R^{K_{1}}+B R^{K_{2}}+q K_{3}-\frac{q K_{4}}{R^{2}}\right) \\
-\frac{A^{\prime}}{2}(1+v)+\frac{B^{\prime}}{R^{2}}(1-v)=0 \\
\varphi_{L 1}-\left.\varphi_{L 2}\right|_{r=R}=A R^{K_{1}}+B R^{K_{2}}+q K_{3}-\frac{q K_{4}}{R^{2}}-\left(\frac{A^{\prime} R}{2}+\frac{B^{\prime}}{R}\right)=0 \\
\omega_{L 1}-\left.\omega_{L 2}\right|_{r=R}=-\frac{A R^{K_{1}+1}}{K_{1}+1}-\frac{B R^{K_{2}+1}}{K_{2}+1}-K_{3} q R-\frac{K_{4} q}{R}+C+\frac{A^{\prime} R^{2}}{4}+B^{\prime} \ln \frac{R}{a}-C^{\prime}=0
\end{gathered}
$$

\subsubsection{Calculation of $C T F^{B}$}

Combining Eqs. (28)-(30), and (32)-(34), six integration constants can be obtained.

In this work, Matlab was used for the calculation. The total strain energy $U_{L}$ of the UPCL can be obtained using the superposition principle of the linear elastic regime:

$$
\delta U_{L}=\frac{\partial\left(U_{L 1}+U_{L 2}\right)}{\partial a_{L}} \delta a_{L}
$$

The work done by $q$ is: 


$$
W_{L}=\int_{0}^{2 \pi} \int_{b}^{R} q \omega_{L 1} r \mathrm{~d} r \mathrm{~d} \theta \Rightarrow \delta W_{L}=\frac{\partial W_{L}}{\partial a_{L}} \delta a_{L}
$$

The strain energy absorbed by the crack propagation during mode B delamination can be described as:

$$
U_{d L}=G_{I C} \pi\left(a_{L}^{2}-R^{2}\right) \Rightarrow \delta U_{d L}=G_{I C} 2 \pi a_{L} \delta a_{L}
$$

Substituting Eq. (35)-(37) into Eq. (5), a detailed $q$ value can be obtained through Matlab calculation.

Therefore, the $C T F_{c l}^{B}$ can be obtained:

$$
C T F_{c l}^{B}=q \pi\left(R^{2}-b^{2}\right)
$$

The total CTF of mode B delamination $C T F^{B}$ is as follows:

$$
C T F^{B}=\frac{q \pi\left(R^{2}-b^{2}\right)}{1-\gamma}
$$

\section{Experimental setup}

\subsection{Fabrication of AFRP laminates}

AFRP laminates were made of K-29 high strength aramid fibers (supplied by DuPond) impregnated with epoxy resin having 60\% fiber volume fractions. K-29 has been used for structural aircraft components, personal body armors, and ballistic head protections. Laminates with two different thicknesses (15 and 8 plies, respectively), were used for the delamination test and DCB test, respectively. The thickness of each ply of the laminate is $0.27 \mathrm{~mm}$. All laminates were first cured in an autoclave at $80^{\circ} \mathrm{C}$ for $30 \mathrm{~min}$, and then at $120^{\circ} \mathrm{C}$ for $120 \mathrm{~min}$. The mechanical properties of the woven AFRP composites are listed in Table 3.

The workpiece used in this study were produced by water jet cutting to achieve the 
desired dimensional accuracy and machining quality [32-33]. The influence of water transport on the AFRP laminate surface has been studied in detail in the literature [34]. In this study, the traverse speed during the water jet cutting was $400 \mathrm{~mm} / \mathrm{min}$ and corresponding area for moisture absorption during the water jet cutting is negligible. The surface of the cut workpiece was wiped dry after cutting, and the workpiece were further dried under the room temperature for $48 \mathrm{~h}$ before further testing.

3.2 Mode I interlaminar fracture toughness, $G_{I C}$

In order to obtain $G_{I C}$ of the AFRP, DCB tests were conducted in accordance with ASTM D5528. The experimental setup and the dimensions of the specimens are shown in Fig. 10. The test was carried out on a universal testing machine (AGS-X-50KND, Shimadzu) at a constant loading speed of $1 \mathrm{~mm} / \mathrm{min}$. The initial crack is prefabricated in the middle of the laminate end using a $20 \mu \mathrm{m}$ thick, and $50 \mathrm{~mm}$ long Teflon film. To observe the progresses of the crack growth during testing, the specimen was marked at $5 \mathrm{~mm}$ intervals from the tip of the Teflon film, see Fig 10. The average $G_{I C}$ value (based on five tests) is $295.95 \pm 32.71 \mathrm{~J} / \mathrm{m}^{2}$.

\subsection{Drilling experiments}

Fig. 11 shows the drilling experimental setup. The experiments were carried out on a XK714D computer numerical control (CNC) machine tool under dry condition. Blind holes were drilled on $160 \times 100 \times 4.1 \mathrm{~mm}$ AFRP laminates with back support at the feed rate of $20 \mathrm{~mm} / \mathrm{min}$ and spindle speed of $1000 \mathrm{rpm}$, and the number of the uncut plies remain under the chisel edge varies from 1 to 3 . Uncoated solid carbide twist drills were used in this study. The geometric parameters of the tool are summarized in Table 4. In the preliminary research, no edge chipping occurred after drilling 3 holes. 
However, after drilling 5 holes, edge chipping and severe adhesive wear have been found on the cutting lip and the flank face, respectively. In order to minimize the effects of tool wear on the thrust force, tool bit was replaced after drilling every three holes in this study.

The delamination tests were performed after drilling, at a feed rate of $5 \mathrm{~mm} / \mathrm{min}$ on the same experiment platform without back support. The relatively low feed velocity was chosen as it allows the dynamometer to better capture the dynamic variation of the thrust force during the tests and hence provides a more accurate data acquisition. Each experiment with the same number of UPCE was repeated three times. During the delamination tests, the dynamic thrust forces were measured by a dynamometer (9257B, Kistler), which was connected to a 5070A charge amplifier and a data acquisition card.

The data were processed by the program Dynoware.

\section{Model validation and discussion}

\subsection{Experimental analysis of CTFs}

Fig. 12 illustrates a typical thrust force curve recorded during a delamination test with 3 UPCE. It can be seen that with the application of the thrust force, the curve shows a linear increase up to point A, which represents the total CTF of mode A delamination [29]. When mode A delamination propagates, there is no material to support the UPCE to restrain the delamination propagation, hence the thrust force gradually decreases towards the end of the test.

In addition, several sudden drops of the thrust force (such as point B) occurred during the linear increase in the thrust force curve. Drill corner is the outermost point of the 
cutting lips, which is in contact and shapes the machined hole wall during drilling. Past literature suggests that the delamination crack originates from the drill corner, not at the web (chisel edge) diameter of the drill $[19,35]$. Fig. 13 gives the schematic illustration of the drill / material contact and stress states of model B delamination. As is shown in Fig. 13(a), under action of load $q$ (generated by the cutting edge of drill corner), the aramid fiber of UPCL experiences elastic deformation. The constraint of the fiber to resist deformation is mainly dependent on the interfacial bonding strength between the fiber and the unmachined region adjacent to the drill corner. Once the thrust force exceeds the critical value, interfacial fracture will occur and crack will immediately propagate to the unmachined region, leading to the onset of delamination. Therefore, the first drop on the thrust force curve caused by the sudden loss of strength represents the total CTF of mode B delamination. As shown in Fig. 13(b), there are subsequent drops in the thrust force after the first drop. This phenomenon can be attributed by the resin rich areas in the AFRP laminates (Fig. 13(c)). Due to the weaker mechanical properties of the resin, the delamination crack is usually initiated and propagates in a resin rich area. Therefore, the subsequent drops on the thrust force curve can be related to the occurrence and propagation of the cracks in the resin rich areas in UPCL. The experimental results of the total CTFs are listed in Table 5. In the case of 1 layer of UPCE, only the total CTF of the mode A delamination is considered as the thrust forces linearly increase up to point A without sudden drops.

\subsection{Determination of the chisel edge ratio}

The chisel edge ratio $(\gamma)$ is an important factor in establishing analytical model for 
delamination. However, to date there has been no quantitative index defined in the literature to determine $\gamma$. In this paper, in order to accurately determine $\gamma$ in drilling of AFRP, a quantitative index is proposed based on the degree of similarity between the experimental and theoretical values. As for mode A delamination with different number of UPCE $(i=1,2,3)$, Euclidean distance is used to evaluate similarity between the average experimental data $C T F_{i}^{A(\exp )}$ and $C T F_{i}^{A(\text { pred })}$ with their corresponding theoretical values as a function of $\gamma$. Euclidean distance can be expressed as:

$$
d=\sqrt{\sum_{i=1}^{3}\left(C T F_{i}^{A(\exp )}-C T F_{i}^{A(\text { pred })}\right)^{2}}
$$

The smaller the Euclidean distance, the better the similarity, hence the greater accuracy of the model. As shown in Fig. 14, the best fitting is when $\gamma=0.24$. Since the maximum relative deviation between modeling and experimental data is around $20 \%$ ( $d=245.1$ ) for $0.2 \leq \gamma \leq 0.3$, a reasonable level of fitting can also be achieved in this range. Therefore, we focused on this range $(0.2 \leq \gamma \leq 0.3)$ in the subsequent analysis.

\subsection{Delamination model analysis}

Fig. 15 compares the predictive CTF component values in two different delamination scenarios. Based on Eq. (13), Fig. 15(a) shows that $C T F_{c e}^{A}$ increases with increasing $i$ as a result of the increasing bending stiffness of the UPCE. In particular, $C T F_{c e}^{A}$ $(i=3)$ is more than four times greater than that of $\operatorname{CTF}_{c e}^{A} \quad(i=1)$. According to Eq. (39), the influence of $\gamma$ on $C T F_{c l}^{B} \quad(i=1,2,3)$ is shown in Fig. 15(b). It can be seen that $C T F_{c l}^{B}$ decreases with increasing $\gamma$. According to Eq. (2), the component $F_{c e}$ will increase with $\gamma$ under constant thrust force, and the deflection of the UPCE will also increase. In this situation, the supporting effect of the UPCE to the UPCL is 
weakened, which leads to decreased $C T F_{c l}^{B}$. Moreover, it can be observed that the $C_{c l}^{B}$ decreases with decreasing $i$ due to the reduction in the thickness of UPCE and the reduction of its supporting ability. When $\gamma=0.24$ (best point of fit in Fig. 14), the predictive value of $C T F_{c l}^{B}$ dropped as $i$ decreased from 3 to $1(328.16 \mathrm{~N}$ to 309.85 $\mathrm{N}$ then drastically decreases to $198.85 \mathrm{~N}$ ).

In order to analyze the occurrence of mode $\mathrm{A}$ and mode $\mathrm{B}$ delamination, the comparison of the total CTFs for the two different modes of delamination under the same drilling process is illustrated in Fig. 16. For selected values of $\gamma(0.2,0.24,0.3)$, the following relationships apply:

$$
\left\{\begin{array}{l}
\operatorname{CTF}^{A}<C T F^{B},(i=1) \\
C_{T F^{A}}>C T F^{B},(i=2,3)
\end{array}\right.
$$

It can be concluded that mode A delamination is more likely to occur as compared to mode B delamination for $\operatorname{UPCE}(i=1)$. When $i$ exceeds 1 , mode B delamination is more likely to occur. Models proposed in the past literatures usually attribute the holewall delamination to mode A delamination with large number of UPCE, hence they mostly underestimate the chance of the hole-wall delamination. The present model is more representative of the actual machining process where the hole-wall delamination is more likely to occur as mode B delamination.

\subsection{Model validation and comparison}

Fig. 17 shows the comparison of the experimental results and the predictive total CTF from mode A and mode B delamination as a function $\gamma$. It can be seen that the best fit is found for $\gamma=0.24$, i.e., thrust force exerted by the chisel edge accounts for $24 \%$ of the total load. The contributions of the chisel edge and cutting lips have been investigated by several researchers in the context of CFRP drilling in the past. For 
instance, the contribution of the chisel edge suggested by Zitoune and Collombet ranges from $40 \%$ to $50 \%$ [36]. In contrast, the chisel edge contribution in our study is significantly lower. The difference might be due to the different mechanical properties of the composites used (hence different $\gamma$ ). In addition, the twist drill used in this study has an inclining chisel edge, hence reducing the thrust force component of the chisel edge to a certain extent.

The comparison of different delamination models proposed in the literatures is shown in Fig. 18. As the existing models are based on the assumption that all the loads are exerted on the UPCE, only mode A delamination in the present work is used for comparison. It can be seen that the most conservative CTF prediction is by Ho-Cheng and Dharan's model where the assumptions were based on isotropic material and point load [14]. Although the anisotropy of the workpiece has been considered in Zhang's model [22], the predictive values of the CTF is still too low comparing to the experimental results. Lachaud's model [23] consists of two hypothetical loads, i.e., uniformly distributed load and point load. Although the distributed load model is better than the point load model, it still shows significant deviation from the experimental results. The comparison confirms that our proposed model best agrees with the experimental values.

\section{Conclusions}

Considering the role of thrust force on the actual drill-material interaction mechanisms, a novel analytical model is proposed in this study for more accurate CTF prediction in the context of AFRP drilling. New delamination regime was first proposed based on the actual chisel edge-material interaction mechanism and the actual cutting lips-material interaction mechanism and two modes of delamination (chisel edge 
delamination and drill corner delamination) were both considered for establishing the new model. DCB and delamination tests have been carried out to validate the proposed analytical model. A quantitative index for the determination of the chisel edge ratio has been obtained by evaluating the degree of similarity between the experimental and the theoretical values. The results show that thrust force exerted by the chisel edge accounts for $24 \%$ of the total load in AFRP drilling. The comparison with existing delamination models confirms the proposed model agrees well with the experimental data. The mode of delamination during drilling of AFRP depends on the number of uncut plies under the chisel edge: mode A delamination is more likely to occur than the B delamination when there is 1 uncut ply under the chisel edge; In the case of 2 and 3 uncut plies, mode B delamination is more likely to be induced.

\section{Acknowledgments}

This project has received funding from the National Natural Science Foundation of China (Grant No. 51705362), the Natural Science Foundation of Tianjin (Grant No. 18JCQNJC75600), the Science \& Technology Development Fund of Tianjin Education Commission for Higher Education (Grant No. 2017KJ081), and the European Union's Horizon 2020 research and innovation program (Grant No. 734272). The authors also thank Chinese Scholarship Council for funding support (Contract No. 201808120102).

\section{References}

1. Yilbas BS, Akhtar SS. Laser cutting of Kevlar laminates and thermal stress formed at cutting sections. Opt Laser Eng 2012;50:204-9.

2. Sun D, Lemoine P, Keys D, Doyle P, Malinov S, Zhao Q, Qin XD, Jin Y. Hole- 
making processes and their impacts on the microstructure and fatigue response of aircraft alloys. Int J Adv Manuf Technol 2016;94:1719-26.

3. Wu LF, Zhu JG, Xie HM. Investigation of residual stress in 2D plane weave aramid fibre composite plates using moiré interferometry and hole-drilling technique. Strain 2015;51:429-43.

4. Won MS, Dharan CKH. Drilling of aramid and carbon fibre polymer composites. J Manuf Sci Eng 2002;124(4):778-83.

5. Bhattacharyya D, Horrigan DPW. A study of hole drilling in Kevlar composites. Compos Sci Technol 1998;58:267-83.

6. Shuaib AN, Al-Sulaiman FA, Hamid F. Machinability of Kevlar 49 composite laminates while using standard TiN coated HSS drills. Mach Sci Technol $2004 ; 8: 449-67$.

7. Gao H, Zhuang Y, Wang B, Huang JL. Study on the Combined Machining Technology of Sawing and Grinding for Drilling Aramid/Epoxy Composites. Adv Mater Res 2012;565:436-41.

8. Zheng L, Zhou H, Gao C, Yuan J. Hole drilling in ceramics/Kevlar fiber reinforced plastics double-plate composite armor using diamond core drill. Mater Des $2012 ; 40: 461-6$

9. Díaz-Álvareza A, Rodríguez-Millán M, Díaz-Álvarez J, Miguélez MH. Experimental analysis of drilling induced damage in aramid composites. Compos Struct 2018;202:1136-44.

10. Bao YJ, Hao W, Gao H, Liu XS, Wang YQ. Numerical and experimental 
investigations on temperature distribution of plain-woven aramid fiber-reinforced plastics composites with low-mild spindle velocities. Int J Adv Manuf Technol 2018;99: 613-22.

11. Anarghya A, Harshith DN, Rao N, Nayak NS, Gurumurthy BM, Abhishek VN, Patil IGS. Thrust and torque force analysis in the drilling of aramid fibre-reinforced composite laminates using RSM and MLPNN-GA. Heliyon 2018;4:1-39.

12. Liu SN, Yang T, Liu C, Du Y. Comprehensive investigation of cutting mechanisms and hole quality in dry drilling woven AFRP with typical tools. Proc IMechE, Part B: J of Engineering Manufacture. https://doi.org/ 10.1177/0954405419844855.

13. Soepangkat BOP, Pramujati B, Effendi MK, Norcahyo R, Mufarrih AM. Multiobjective optimization in drilling Kevlar fiber reinforced polymer using grey fuzzy analysis and backpropagation neural network-genetic algorithm (BPNN-GA) approaches. Int J Precis Eng Manuf 2019;20:593-607.

14. Ho-Cheng H, Dharan CKH. Delamination during drilling in composite laminates. J Eng Ind 1990;112(3):236-9.

15. Capello E. Workpiece damping and its effect on delamination damage in drilling thin composite laminates. J Mater Process Technol 2004;148(2):186-95.

16. Wang HJ, Sun J, Li JF, Li WD. Investigation on delamination morphology during drilling composite laminates. Int J Adv Manuf Technol 2014;74:257-66.

17. Fu R, Jia ZY, Wang FJ, Jin Y, Sun D, Yang LJ, Cheng D. Drill-exit temperature characteristics in drilling of UD and MD CFRP composites based on infrared thermography. Int J Mach Tools Manuf 2018;135:24-37. 
18. Wang GD, Li N, Xiong XH, Chong Q, Li Z, Lu SW. 3D level comprehensive evaluation of hole quality in drilling carbon fiber-reinforced plastics. Int J Adv Manuf Technol 2017;93:2433-45.

19. Girot F, Dau F, Gutiérrez-Orrantia ME. New analytical model for delamination of CFRP during drilling. J Mater Process Tech 2017;240:332-43.

20. Karimi NZ, Heidary H, Minak G. Critical thrust and feed prediction models in drilling of composite laminates. Compos Struct 2016;148:19-26.

21. Qi ZC, Zhang KF, Li Y, Liu SN, Cheng H. Critical thrust force predicting modeling for delamination-free drilling of metal-FRP stacks. Compos Struct 2014;107:6049.

22. Zhang LB, Wang LJ, Liu XY. A mechanical model for predicting critical thrust forces in drilling composite laminates. Proc IMechE, Part B: J of Engineering Manufacture 2001;215:135-46.

23. Lachaud F, Piquet R, Collombet F, Surcin L. Drilling of composite structures. Comput Struct 2001;52:511-6.

24. Rahmé P, Landon Y, Lachaud F, Piquet R, Lagarrigue P. Analytical models of composite material drilling. Int J Adv Manuf Technol 2011;52:609-17.

25. Ojo SO, Ismail SO, Paggi M, Dhakal HN. A new analytical critical thrust force model for delamination analysis of laminated composites during drilling operation. Compos Part B 2017;124:207-17.

26. Ismail SO, Ojo SO, Dhakal HN. Thermo-mechanical modelling of FRP cross-ply composite laminates drilling: Delamination damage analysis. Compos Part B 
2016;108:45-52.

27. Jain S, Yang DCH. Effects of feed rate and chisel edge on delamination in composites drilling. Trans ASME J Eng Ind 1993;115:398-405.

28. Gururaja S, Ramulu M. Modified exit-ply delamination model for drilling FRPs. J Compos Mater 2009;43:483-500.

29. Saoudi J, Zitoune R, Mezlini S, Gururaja S, Seitier P. Critical thrust force predictions during drilling: Analytical modeling and X-ray tomography quantification. Compos Struct 2016;153:886-94.

30. Timoshenko S, Woinowsky-Krieger S. Theory of plates and shells. McGraw-Hill; 1959.

31. Khashabaa UA, El-Keran AA. Drilling analysis of thin woven glass-fiber reinforced epoxy composites. J Mater Process Tech 2017;249:415-25.

32. Wang J, Guo DM. A predictive depth of penetration model for abrasive waterjet cutting of polymer matrix composites. J Mater Process Technol 2002;121(23):390-4.

33. Li MJ, Huang MJ, Chen YW, Gong P, Yang XJ. Effects of processing parameters on kerf characteristics and surface integrity following abrasive waterjet slotting of Ti6A14V/CFRP stacks. J Manuf Process 2019;42:82-95.

34. Cervenka AJ, Bannister DJ, Young RJ. Moisture absorption and interfacial failure in aramid/epoxy composites. Compos Part A 1998;29A:1137-44.

35. Zitoune R. Délaminage lors du perçage d'un composite carbone-époxy. Techniques de l'ingénieur 2013;RE227:1-10. 
36. Zitoune R, Collombet F. Numerical prediction of the thrust force responsible of delamination during the drilling of the long-fibre composite structures. Compos Part A 2007;38:858-66.

\section{Author statement}

We certify that all authors have seen and approved the final version of the manuscript being submitted. We warrant that the article is the authors' original work, hasn't received prior publication and isn't under consideration for publication elsewhere.

37.

\section{Conflict of interest}

The authors declared that they have no conflicts of interest to this work. 38.

\section{Figure Captions}

Fig. 1. Schematic diagram of traditional delamination regime.

Fig. 2. Schematic diagram of the actual drill/material contact.

Fig. 3. Schematic diagram of mechanism describing mode A delamination.

Fig. 4. Schematic diagram of mechanism describing mode B delamination.

Fig. 5. Model of the uncut material under the chisel edge.

Fig. 6. Schematic diagram of the material in the region of mode B delamination.

Fig. 7. Schematic diagram of the APVT: (a) Model analysis based on the theory of classic plate bending, (b) Tool geometry of the drill bit used in this study.

Fig. 8. Schematic diagram of the APET.

Fig. 9. Schematic diagram of conditions at the boundaries and the interface.

Fig. 10. Experimental setup for DCB test. 
Fig. 11. Experimental devices for delamination test.

Fig. 12. The thrust force curve of delamination test with 3 uncut plies under the chisel edge.

Fig. 13. Schematic diagram showing drill / material contact and stress states under model B delamination: (a) initiation of mode B delamination, (b) thrust force curve during delamination test, (c) delamination at the resin rich area.

Fig. 14. Determination of the chisel edge ratio.

Fig. 15. Comparison of the components of CTF under different conditions: (a) CTF components (exerted by the chisel edge) of mode A delamination, (b) CTF components (exerted by the cutting lips) of mode B delamination.

Fig. 16. Comparison of the total CTF of mode A and mode B delamination.

Fig. 17. Comparison of the CTFs between the predictive values and the experimental results:

(a) The CTF of mode A delamination, (b) The CTF of mode B delamination.

Fig. 18. Fitting of experimental data with the existing and present theoretical models. 


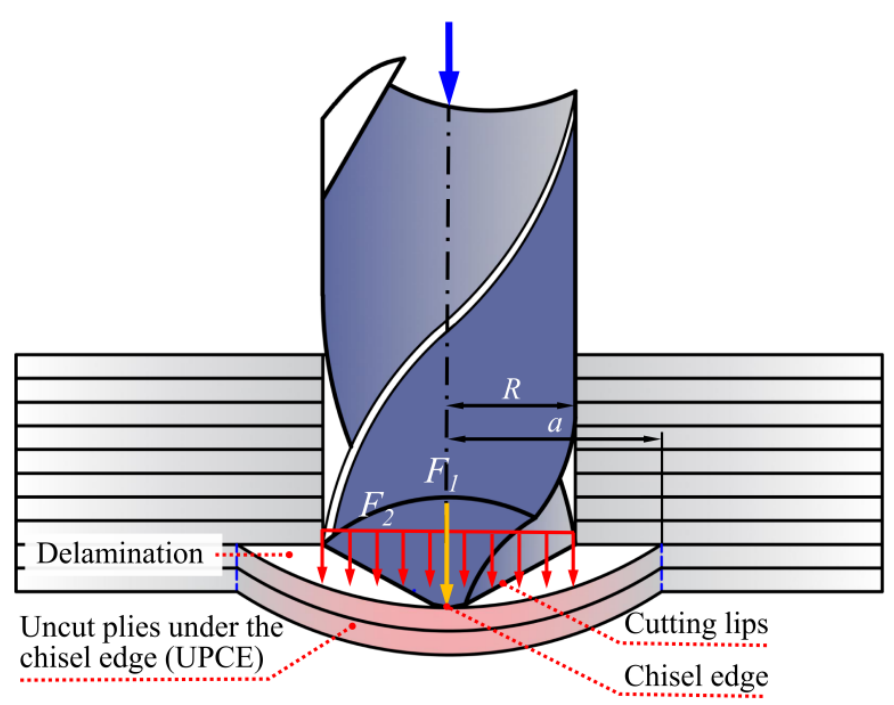

Fig. 1. Schematic diagram of traditional delamination regime.

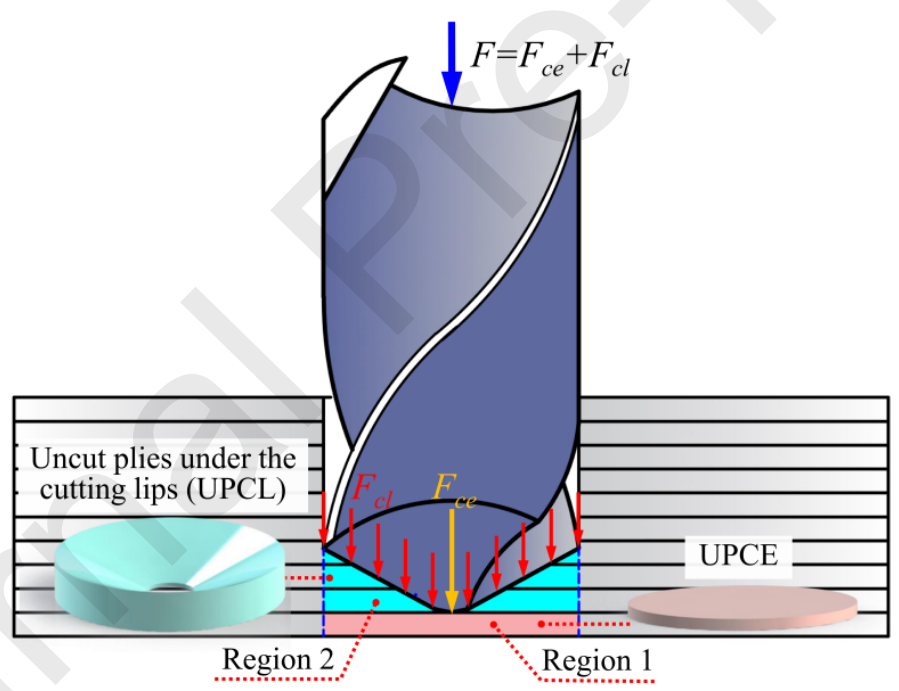

Fig. 2. Schematic diagram of the actual drill/material contact. 


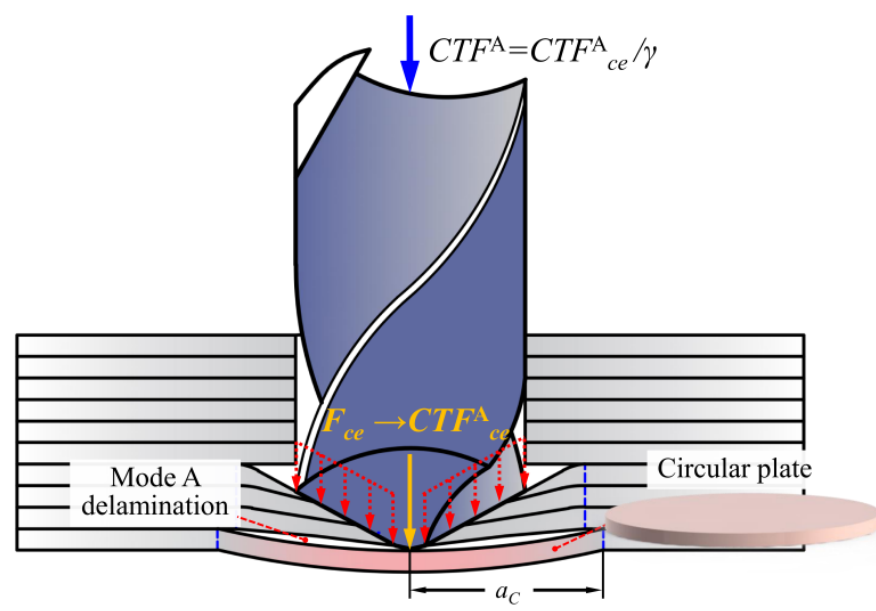

Fig. 3. Schematic diagram of mechanism describing mode A delamination.

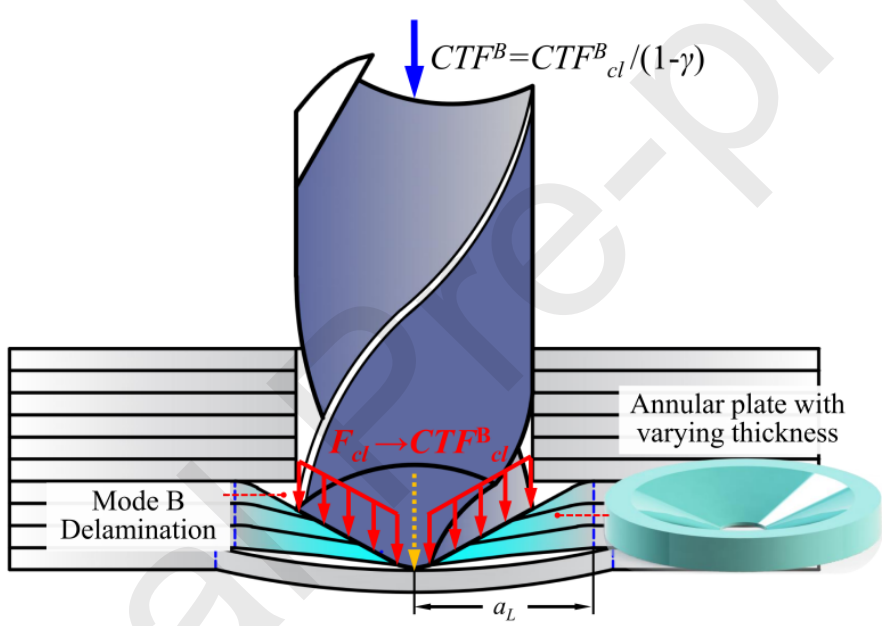

Fig. 4. Schematic diagram of mechanism describing mode B delamination. 


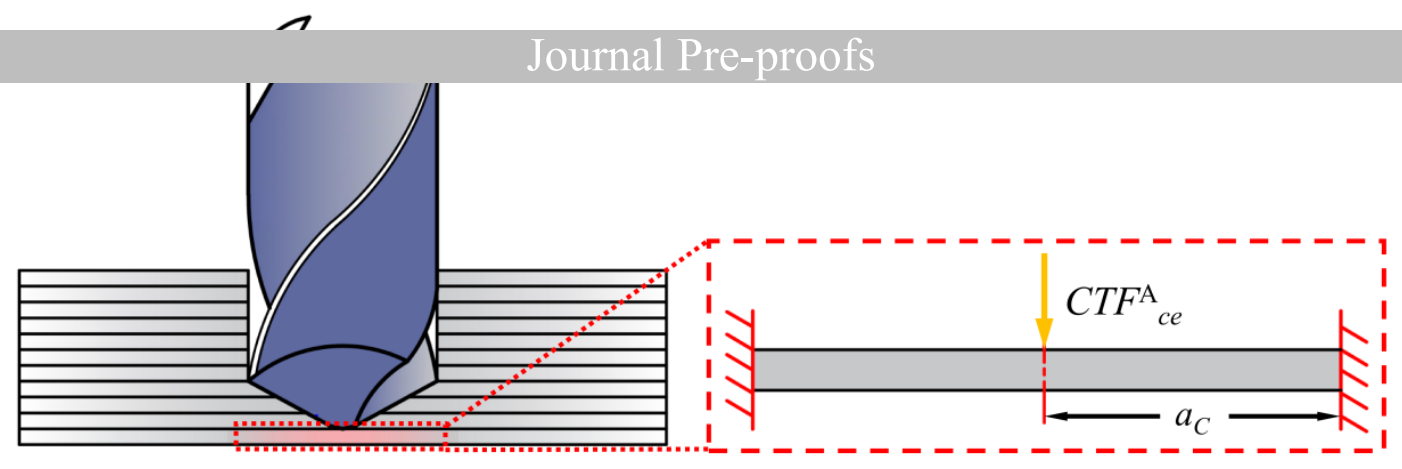

Fig. 5. Model of the uncut material under the chisel edge.

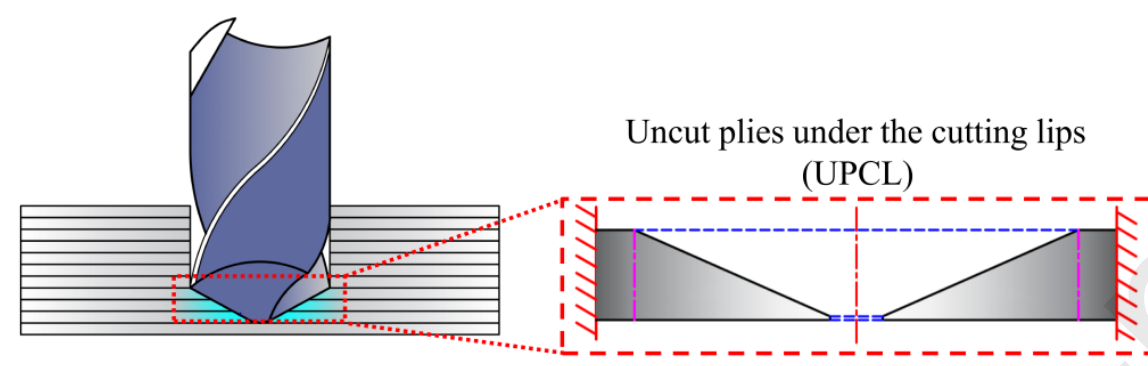

Annular plate with linearly varying thickness

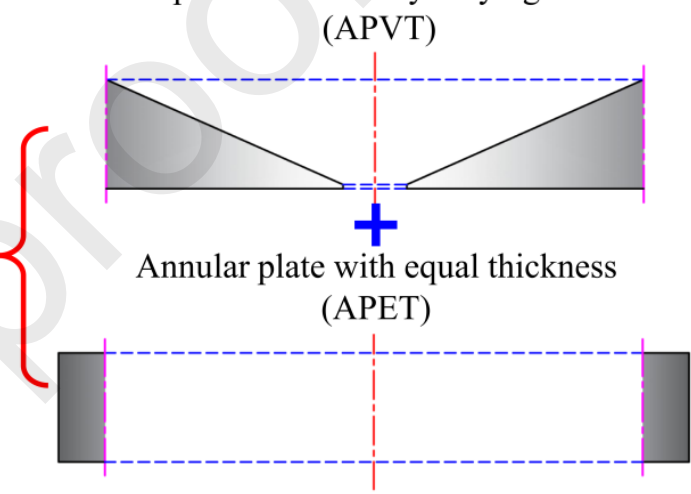

Fig. 6. Schematic diagram of the material in the region of mode B delamination. 


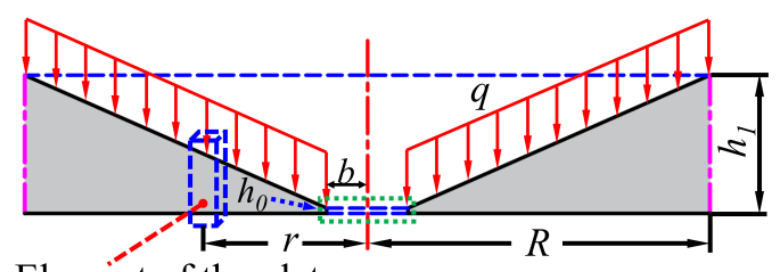

Elemént of the plate

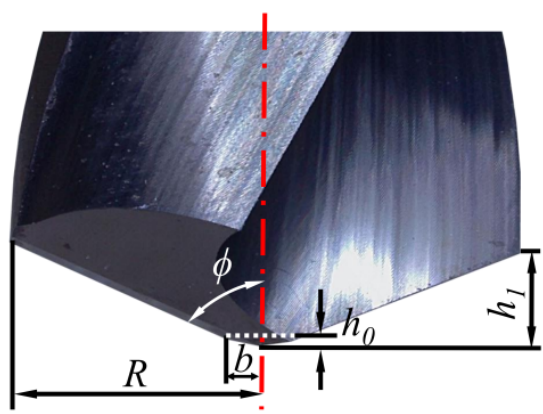

(b)

Fig. 7. Schematic diagram of the APVT: (a) Model analysis based on the theory of classic plate bending, (b) Tool geometry of the drill bit used in this study.

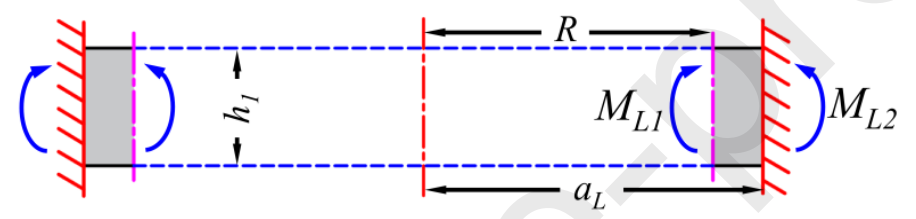

Fig. 8. Schematic diagram of the APET.

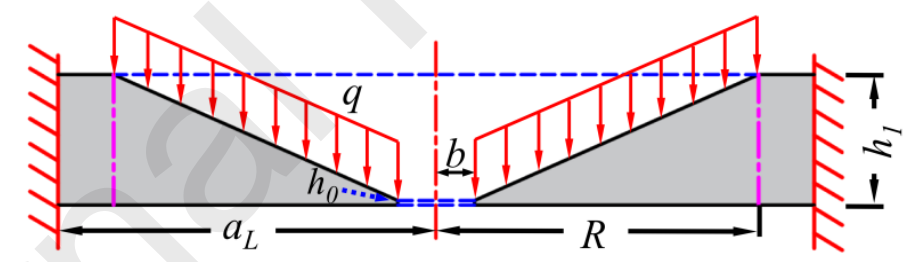

Fig. 9. Schematic diagram of conditions at the boundaries and the interface. 


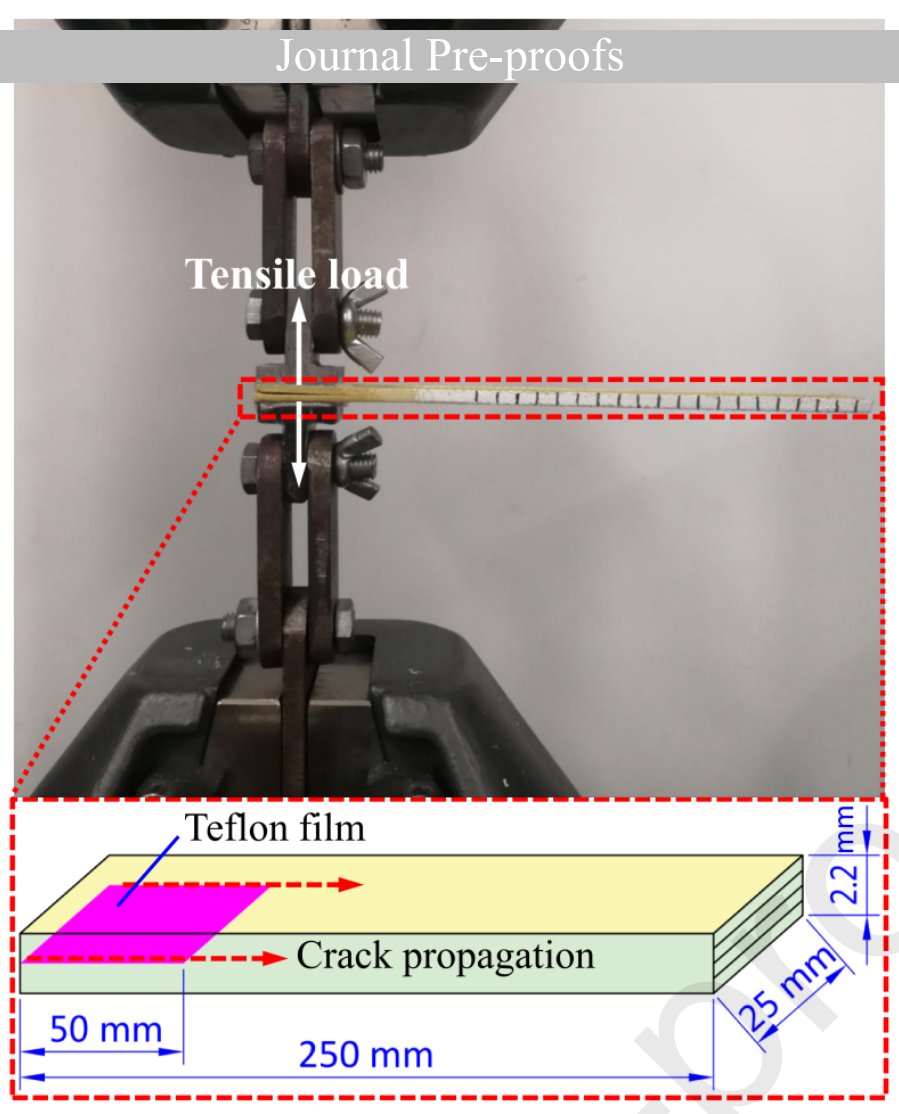

Fig. 10. Experimental setup for DCB test.
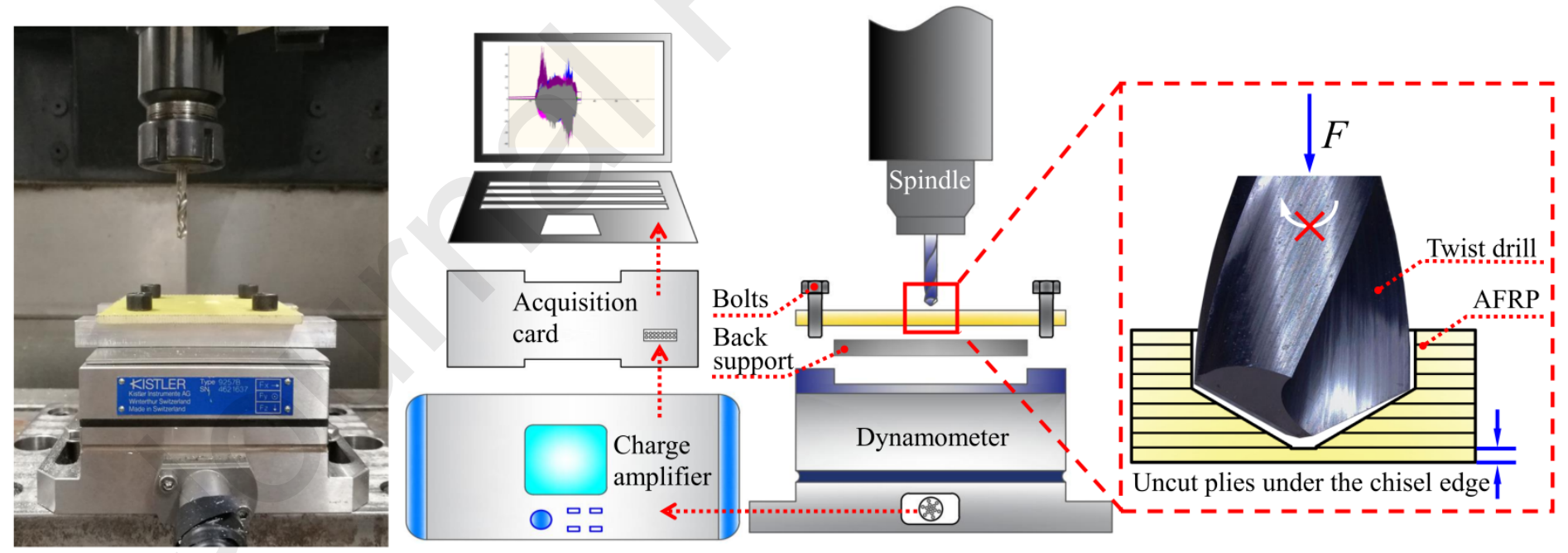

Fig. 11. Experimental devices for delamination test. 


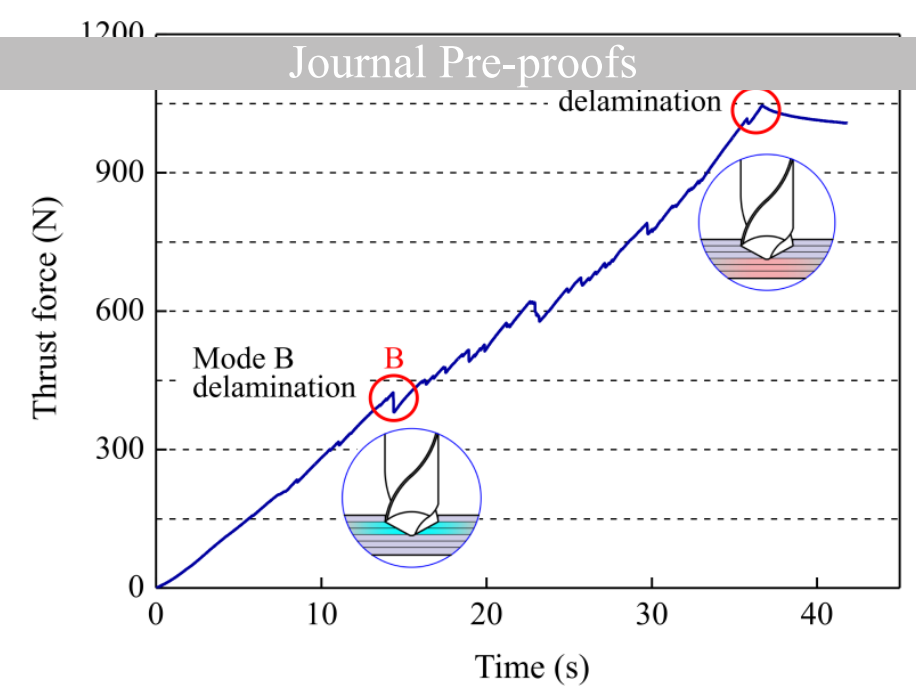

Fig. 12. The thrust force curve of delamination test with 3 uncut plies under the chisel edge.

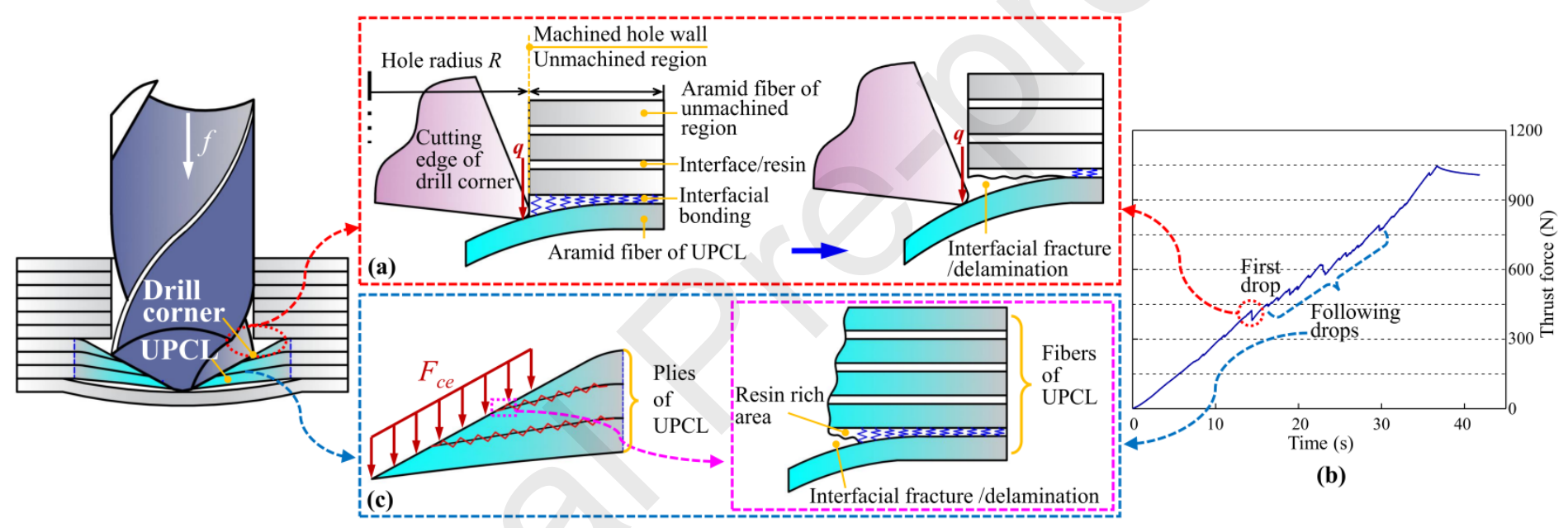

Fig. 13. Schematic diagram showing drill / material contact and stress states under model B delamination: (a) initiation of mode B delamination, (b) thrust force curve during delamination test, (c) delamination at the resin rich area. 


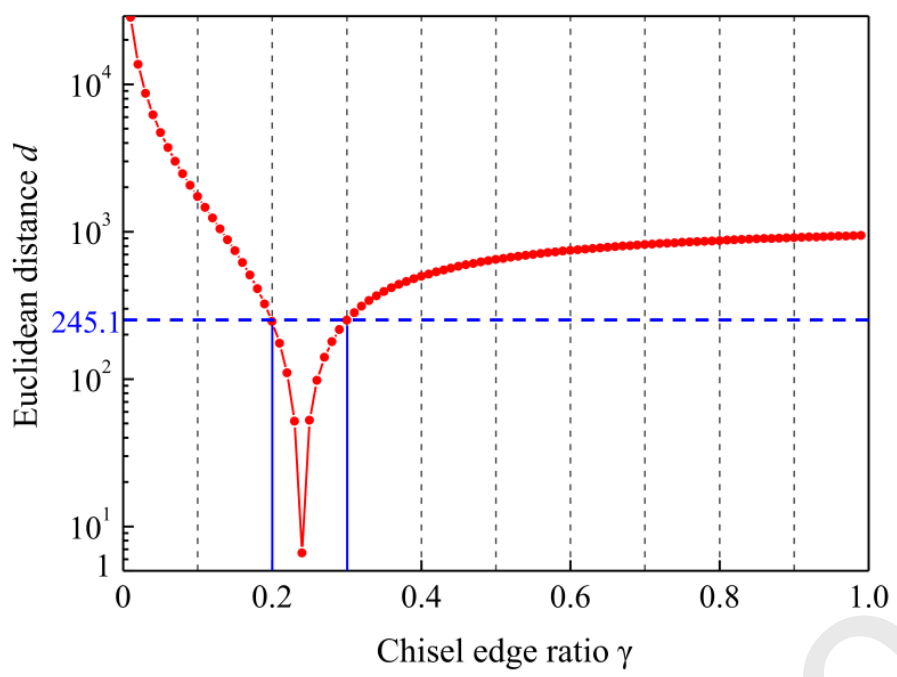

Fig. 14. Determination of the chisel edge ratio.

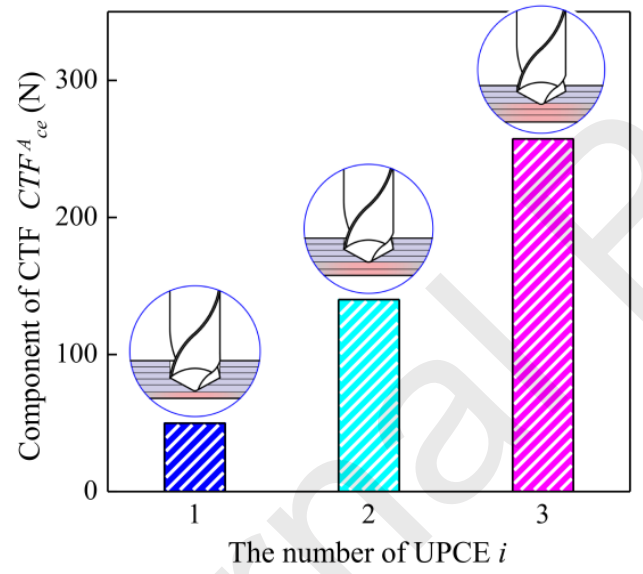

(a)

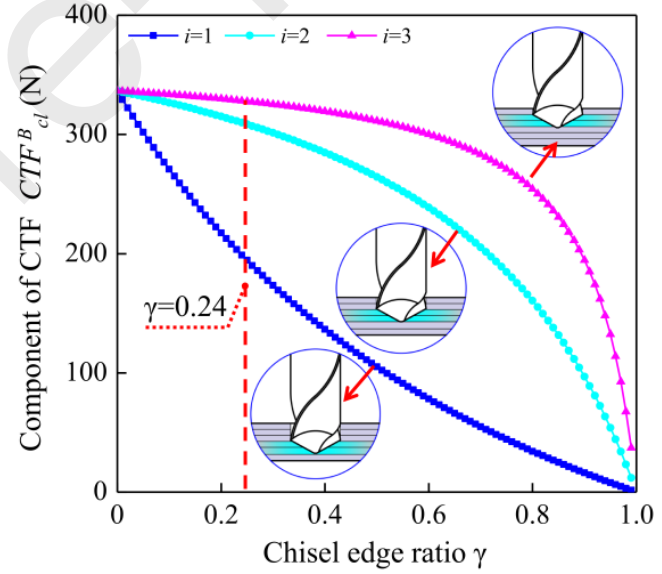

(b)

Fig. 15. Comparison of the components of CTF under different conditions: (a) CTF components (exerted by the chisel edge) of mode A delamination, (b) CTF components (exerted by the cutting lips) of mode B delamination. 


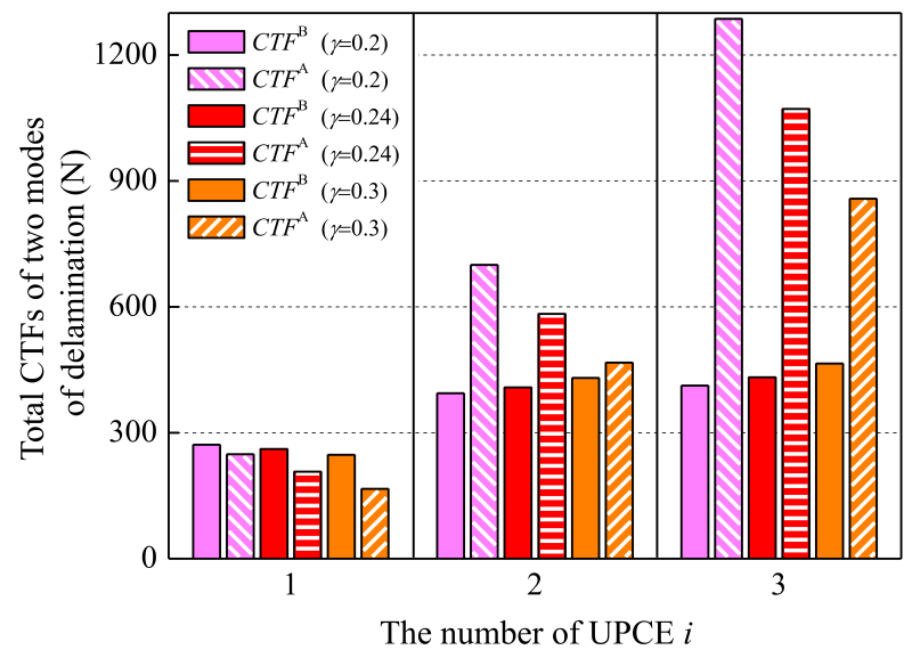

Fig. 16. Comparison of the total CTF of mode A and mode B delamination.

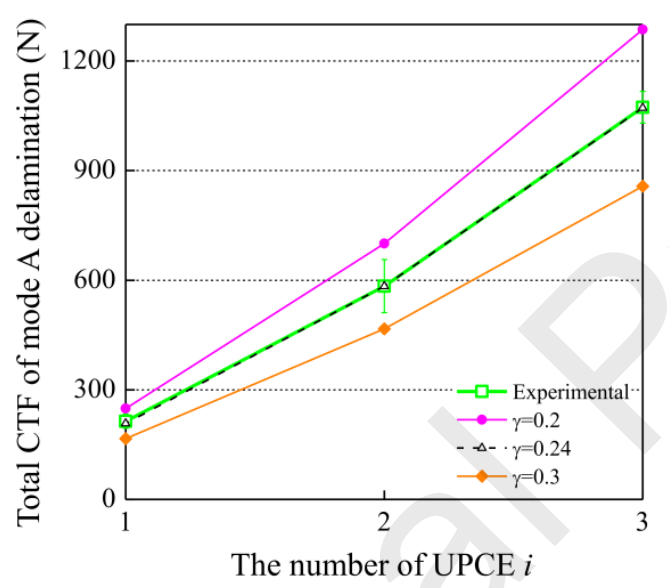

(a)

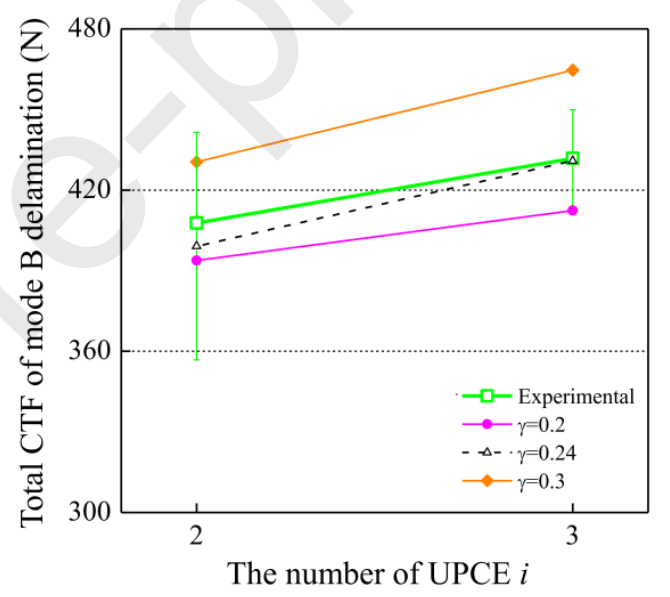

(b)

Fig. 17. Comparison of the CTFs between the predictive values and the experimental results:

(a) The CTF of mode A delamination, (b) The CTF of mode B delamination. 


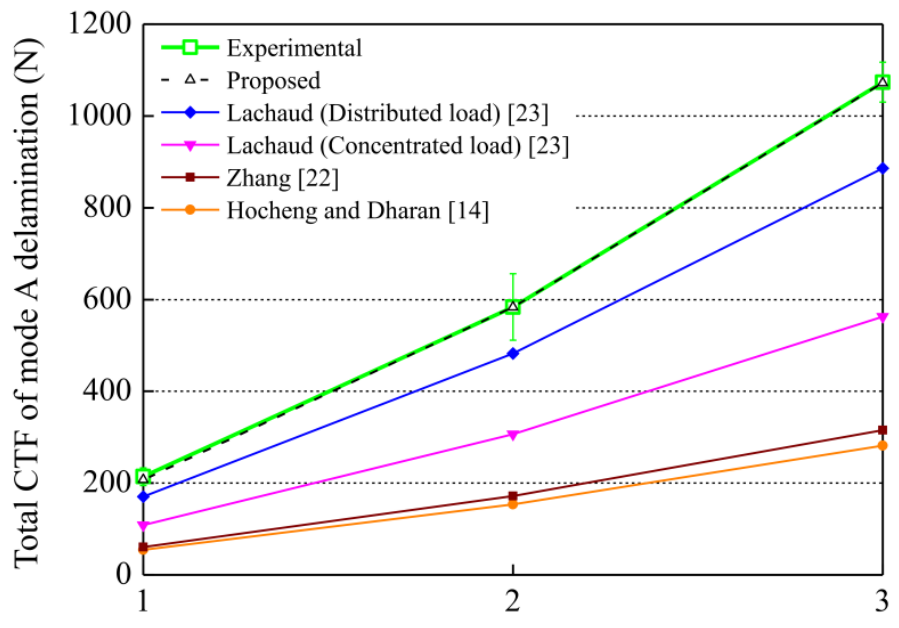

The number of UPCE $i$

Fig. 18. Fitting of experimental data with the existing and present theoretical models.

39.

Table 1

Recent research on AFRP drilling.

\begin{tabular}{|c|c|c|c|}
\hline Reference & Tool geometry & Drilling parameters & Main findings \\
\hline Gao et al. [7] & $\begin{array}{l}\text { Sawing drill and sawing-grinding } \\
\text { drill }(d=30 \mathrm{~mm})\end{array}$ & $\begin{array}{l}f=5 \mathrm{~mm} / \mathrm{min} \\
S=10000 \mathrm{rpm}\end{array}$ & $\begin{array}{l}\text { Hole making process based on } \\
\text { sawing and grinding }\end{array}$ \\
\hline Zheng et al. [8] & $\begin{array}{l}\text { Core drill (sintering diamond, } d=24 \\
\mathrm{~mm} \text { ) }\end{array}$ & $\begin{array}{l}f=\text { Manual step feed } \\
S=1270-3200 \mathrm{rpm}\end{array}$ & $\begin{array}{l}\text { Ceramics/AFRP stack } \\
\text { composite drilling }\end{array}$ \\
\hline $\begin{array}{l}\text { Díaz-Álvarez et } \\
\text { al. [9] }\end{array}$ & $\begin{array}{l}\text { Twist drills and Brad \& Spur drill } \\
\text { (uncoated HSS, } d=6 \mathrm{~mm} \text { ) }\end{array}$ & $\begin{array}{l}f=30.5-584.0 \mathrm{~mm} / \mathrm{min} \\
S=1220-5840 \mathrm{rpm}\end{array}$ & $\begin{array}{l}\text { Prediction of damage } \\
\text { extension }\end{array}$ \\
\hline Bao et al. [10] & Twist drill (solid carbide, $d=6.5 \mathrm{~mm}$ ) & $\begin{array}{l}f=2 \mathrm{~mm} / \mathrm{min} \\
S=1000-3000 \mathrm{rpm}\end{array}$ & $\begin{array}{l}\text { Model for the temperature } \\
\text { distribution }\end{array}$ \\
\hline $\begin{array}{l}\text { Anarghya et al. } \\
{[11]}\end{array}$ & $\begin{array}{l}\text { Twist drill (solid carbide, } d=6-10 \\
\mathrm{~mm} \text { ) }\end{array}$ & $\begin{array}{l}f=50-100 \mathrm{~mm} / \mathrm{min} \\
S=600-1200 \mathrm{rpm}\end{array}$ & $\begin{array}{l}\text { Model of the Neural Network } \\
\text { optimization }\end{array}$ \\
\hline Liu et al. [12] & $\begin{array}{l}\text { Twist drill, burr tool, brad drill } \\
\text { (uncoated solid carbide, } d=6 \mathrm{~mm} \text { ) }\end{array}$ & $\begin{array}{l}f=20-60 \mathrm{~mm} / \mathrm{min} \\
S=2000-6000 \mathrm{rpm}\end{array}$ & $\begin{array}{l}\text { Cutting mechanisms and hole } \\
\text { quality optimization }\end{array}$ \\
\hline $\begin{array}{l}\text { Soepangkat et al. } \\
\text { [13] }\end{array}$ & $\begin{array}{l}\text { Type } \mathrm{S} \text { and type } \mathrm{X} \text { twist drill (HSS } \\
\text { and HSS-Cobalt, } d=10 \mathrm{~mm} \text { ) }\end{array}$ & $\begin{array}{l}f=50-180 \mathrm{~mm} / \mathrm{min} \\
S=1500-2500 \mathrm{rpm}\end{array}$ & $\begin{array}{l}\text { Optimization of multi- } \\
\text { performance characteristics }\end{array}$ \\
\hline
\end{tabular}


Table 2

Existing models of CTF at onset of delamination for CFRP drilling.

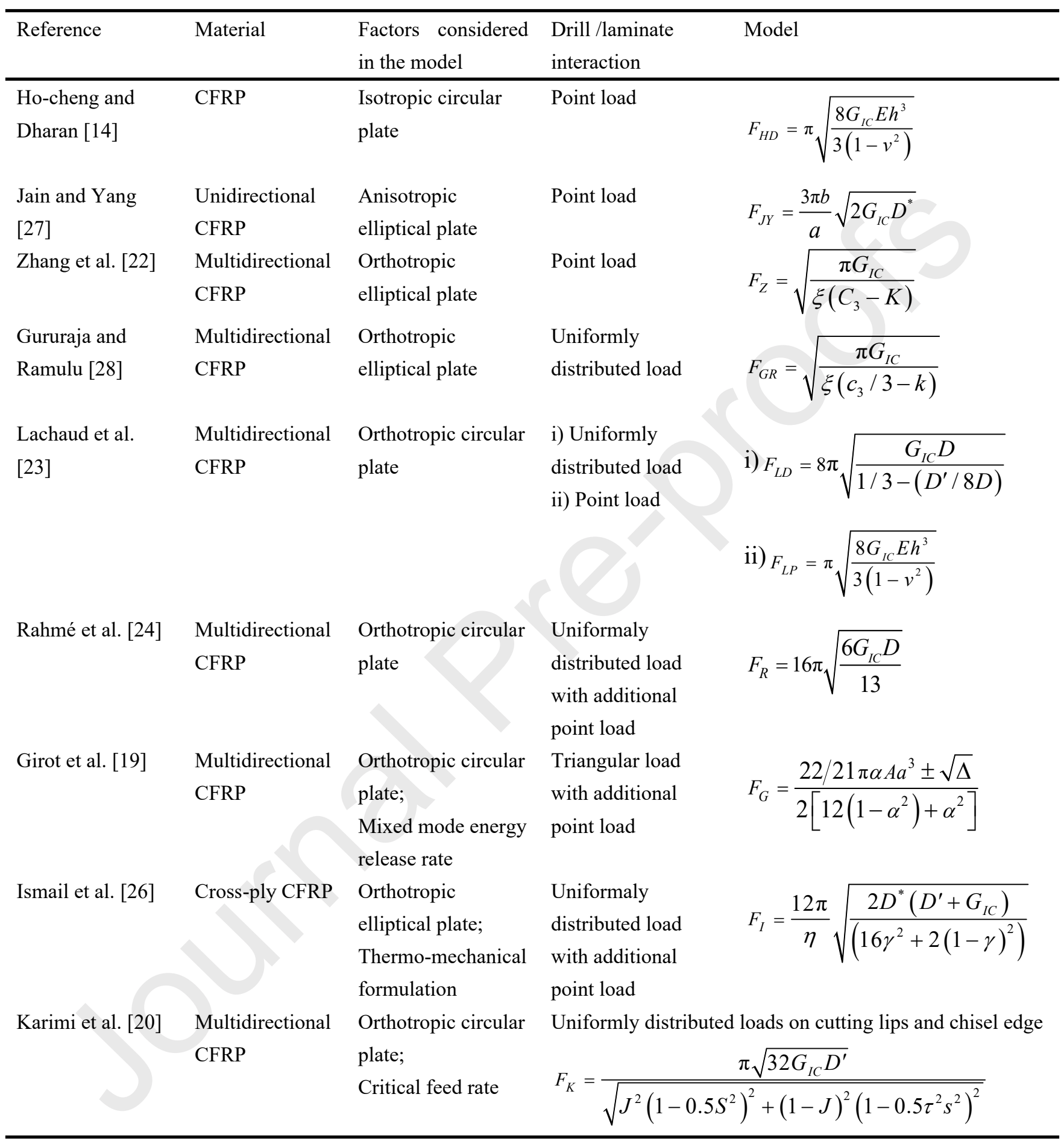


Table 3

Properties of AFRP composite laminates [9].

\begin{tabular}{llll}
\hline$E_{11}(\mathrm{MPa})$ & $E_{22}(\mathrm{MPa})$ & $G_{12}(\mathrm{MPa})$ & $v_{12}$ \\
\hline 18000 & 18000 & 770 & 0.25 \\
\hline
\end{tabular}

\section{Table 4}

Geometric parameters of the twist drill.

\begin{tabular}{lllll}
\hline$R(\mathrm{~mm})$ & 3 \\
$2 \phi$ & $135^{\circ}$ & \\
$h(\mathrm{~mm})$ & 0.54 & $R$ \\
\hline
\end{tabular}

Table 5

CTFs under different conditions.

\begin{tabular}{llllll}
\hline & \multicolumn{3}{c}{ Mode A delamination (Point A) } & \multicolumn{2}{c}{ Mode B delamination (Point B) } \\
\cline { 2 - 6 } Number of UPCE & 1 & 2 & 3 & 2 & 3 \\
\hline Test 1 (N) & 197.63 & 569.18 & 1038.57 & 371.70 & 410.00 \\
Test 2 (N) & 208.95 & 519.41 & 1122.10 & 447.96 & 446.44 \\
Test 3 (N) & 235.38 & 662.35 & 1059.51 & 377.77 & 436.31 \\
Average values (N) & 213.99 & 583.65 & 1073.39 & 399.14 & 430.92 \\
Standard deviation & 19.37 & 72.56 & 43.46 & 42.38 & 18.81 \\
\hline
\end{tabular}

40. 